\title{
Consultoria Colaborativa na Educação Infantil: análise de intervenção envolvendo aluno com autismo
}

\author{
Collaborative Consultation in Early Childhood Education: intervention analysis \\ involving a student with autism
}

Consultoría colaborativa en educación de la primera infancia: análisis de intervención con un estudiante con autismo

Maria da Guia Souza

Mestra pela Universidade Federal do Rio Grande do Norte, Natal, Rio Grande do Norte, Brasil.

guiguia.flor@gmail.com

ORCID - http://orcid.org/0000-0002-5490-9442

Débora Regina de Paula Nunes

Professora doutora na Universidade Federal do Rio Grande do Norte, Natal, Rio Grande do Norte, Brasil. deborareginanunes@yahoo.com

ORCID - http://orcid.org/0000-0001-8758-8916

Recebido em 29 de julho de 2020

Aprovado em 14 de agosto de 2020

Publicado em 17 de novembro de 2020

\section{RESUMO}

Estudos conduzidos no contexto da Educação Infantil (EI) revelam limitações no desenvolvimento escolar e funcional de crianças diagnosticadas com Transtorno do Espectro Autista (TEA). Há evidências de que a formação deficitária de professores se constitui em fator de peso para esses resultados. Nesse contexto, o objetivo do presente estudo foi avaliar os efeitos de um programa de intervenção, delineado como Consultoria Colaborativa, nas práticas de ensino de uma professora da El, que atendia um aluno de 4 anos de idade, diagnosticado com TEA. O programa de consultoria, protagonizado por uma pedagoga, foi desenvolvido em seis etapas e contou com a participação da professora de El, já mencionada, de uma cuidadora e da avó do aluno. Com o apoio de um delineamento de pesquisa multimétodo, envolvendo coleta, análise e integração de dados, de natureza qualitativa e quantitativa, foram avaliados os efeitos do programa de capacitação, no comportamento mediador da professora, como também na participação do aluno com TEA, em três rotinas escolares distintas. Ao término do programa foram registrados aumento na frequência de ocorrência de comportamentos mediadores da docente e mudanças qualitativas na participação do aluno. Registros de validade social indicaram satisfação dos participantes da pesquisa quanto aos efeitos produzidos pelo programa. São colocados em discussão os efeitos promissores das práticas colaborativas na formação docente.

Palavras-chave: Transtorno do Espectro Autista; Educação Infantil; Pesquisa Multimétodo.

\section{ABSTRACT}

Studies conducted in the context of Early Childhood Education (ECE) reveal limitations in the academic and functional development of children diagnosed with Autistic Spectrum Disorder (ASD). Among other factors, this finding is attributed to inadequate teacher 
preparation. In this context, the purpose of the present study was to evaluate the effects of an intervention program, outlined as a Collaborative Consultation, in the teaching practices of an ECE teacher, who attended a 4-year-old student diagnosed with ASD. The program, led by a pedagogue, was developed in six stages and included the ECE teacher, mentioned above, a caregiver and the student's grandmother. A multimethod research design, involving the collection, analysis and integration of qualitative and quantitative data was used to evaluate the effects of the training program on the teacher's mediating behavior, as well as on the student's participation in three different school routines. At the end of the program, an increase in the frequency of teacher-mediating behavior was detected as well as qualitative changes in student participation in the activities. Social validity measures indicated consumers' satisfaction with the outcomes. The promising effects of collaborative practices on teacher education are discussed.

Keywords: Autism Spectrum Disorder; Early Childhood Education; Multimethod Research.

\section{RESUMEN}

Los estudios realizados en el contexto de la Educación de la Primera Infancia (EPI) revelan limitaciones en el desarrollo escolar y funcional de los niños diagnosticados con trastorno del espectro autista (TEA). Hay evidencia de que la educación deficiente de los maestros es un factor importante en estos resultados. En este contexto, el objetivo del presente estudio fue evaluar los efectos de un programa de intervención, descrito como Consultoría Colaborativa, en las prácticas de enseñanza de un maestro de EPI, que atendió a un estudiante de 4 años diagnosticado con TEA. El programa de consultoría, dirigido por un pedagogo, se desarrolló en seis etapas e incluyó la participación del maestro de EPI, mencionado anteriormente, un cuidador y la abuela del estudiante. Se utilizó metodología de investigación de múltiples métodos, que incluía la selección, el análisis y la integración de datos cualitativos y cuantitativos para evaluar los efectos del programa de capacitación en el comportamiento de mediación del maestro, así como en la participación del estudiante en tres rutinas escolares diferentes. Al final del programa, se detectó un aumento en la frecuencia del comportamiento de mediación docente, así como cambios cualitativos en la participación del estudiante en las actividades. Los registros de validez social indicaron la satisfacción de los participantes de la investigación con respecto a los efectos producidos por el programa. Se discuten los prometedores efectos de las prácticas colaborativas en la formación docente.

Palabras clave: Trastorno del Espectro Autista; Educación de la Primera Infancia; Investigación Multimétodo.

\section{Introdução}

O Transtorno do Espectro Autista (TEA) é um distúrbio de natureza neurobiológica, caracterizado por prejuízos sociocomunicativos e comportamentais. Resultados de pesquisas internacionais apontam que uma a cada 54 crianças, de quatro a oito anos de idade, apresentam esse diagnóstico (MAENNER et al., 2020).

Estima-se que, residindo no Brasil, há mais de dois milhões de pessoas com TEA, sendo que expressiva parte dessa população é constituída de crianças que frequentam as classes regulares. Nas escolas estaduais do Rio Grande do Norte, a Secretaria Estadual 
de Educação computa a matrícula de mais de 800 alunos com TEA. Esse quantitativo equivale a mais de $15 \%$ do contingente de alunos considerados público-alvo da Educação Especial do Estado (RIO GRANDE DO NORTE, 2020).

Resultados de pesquisas nacionais sugerem que, apesar do acesso à educação, alunos diagnosticados com autismo, inseridos em ambientes regulares do ensino, apresentam limitado progresso acadêmico e funcional (NEVES et al., 2014; NUNES; AZEVEDO; SCHMIDT, 2013; AZEVEDO; NUNES, 2018). Dentre outros fatores, esses prejuízos decorrem da formação deficitária de professores e do manejo inapropriado de práticas pedagógicas, nem sempre consideradas eficazes para essa população escolar (NUNES et al., 2013; NOZI; VITALIANO, 2012; SCHMIDT et al., 2016; RIBEIRO; MELO; SELLA, 2017).

Com a extinção das habilitações dos Cursos de Pedagogia, a capacitação de professores certificados para atenderem alunos com deficiência tem sido, primordialmente, por meio de programas de formação em serviço, de curta duração (MICHELS, 2011). A literatura sugere, entretanto, que muitos desses programas têm sido ineficazes para o desenvolvimento de habilidades e competências necessárias para a escolarização desse alunado. Pesquisas dessa natureza salientam que, mesmo após a realização dos cursos de formação em serviço, se perpetuam sentimentos de isolamento e inadequação dos docentes para lidar com as demandas dos alunos (MENDES; ALMEIDA; TOYODA, 2011; NUNES; SCHMIDT, 2019).

Considerando as fragilidades desse modelo formativo, pesquisadores têm adotado a Consultoria Colaborativa como uma das alternativas para capacitar docentes e disseminar o uso de estratégias eficazes de ensino na escola regular (MENDES et al., 2011; CANABARRO, 2018; FOLHA; MONTEIRO, 2017; OLMEDO, 2015; SANT'ANNA; MANZINI, 2018). Essa prática, descrita na literatura desde a década de 1990, é configurada como modalidade indireta de prestação de serviços, na qual um consultor do setor da Educação Especial fornece orientações pedagógicas a professores do ensino regular. Seguindo protocolos específicos, cabe ao consultor observar a prática docente e assessorar o professor na maximização do desenvolvimento educacional do aluno. O enfoque igualitário, que alicerça esse modelo permite que o consultado acate ou não as orientações fornecidas. Esse processo interativo viabiliza não apenas a resolução de problemas imediatos de sala de aula, como também o desenvolvimento de competências e habilidades nos professores (CANABARRO, 2018; MENDES et al., 2011). 
http://dx.doi.org/10.5902/1984686X48492

Tendo em vista o ingresso, cada vez mais precoce de educandos com TEA nas escolas brasileiras, é pertinente investigar o que a literatura nacional tem registrado sobre o uso da Consultoria Colaborativa no contexto da Educação Infantil. Assim, foi conduzida uma pesquisa de revisão da literatura sobre esse tópico investigativo, tendo como apoio tanto o Portal de Periódicos, quanto o Portal de Teses e Dissertações, ambos da Coordenação de Aperfeiçoamento de Pessoal de Nível Superior (CAPES). Nessas plataformas foram empreendidas buscas, em teses, dissertações e em periódicos revisados por pares, disponibilizados nos últimos cinco anos.

Os termos de busca incluíram três conjuntos de palavras, em português: (a) "autis" ou "Transtorno do Espectro do Autismo" (b) "educação infantil" ou "creche" ou "ensino infantil" e (c) "consultoria colaborativa" ou "consultoria". Como critério de inclusão foram considerados apenas estudos, dentre os quais a Consultoria Colaborativa foi implementada no contexto do Ensino Infantil, envolvendo alunos com TEA e seus professores. Foram excluídas as pesquisas conduzidas fora do Brasil, as desenvolvidas com outras populações e os estudos de natureza teórica.

Dois estudos atenderam aos critérios de inclusão, conforme assinalados. No primeiro estudo, desenvolvido por Olmedo (2015), o consultor foi uma fonoaudióloga, responsável pela capacitação de três professoras e duas mediadoras, na utilização de recursos de Comunicação Alternativa e Ampliada (CAA), com alunos diagnosticados com TEA, em ambiente de creche. Com base nas demandas formativas das docentes, um programa de formação em CAA foi elaborado, envolvendo atividades teóricas e práticas, conduzidas ao longo de sete meses. Registros observacionais e dados de questionários revelaram aumento na frequência de episódios de interações comunicativas com os alunos quando, após a capacitação, a CAA foi incorporada à prática docente.

No estudo de Canabarro (2018), foram avaliados os efeitos da Consultoria Colaborativa no senso de autoeficácia ${ }^{1}$ de uma professora de educação especial que atuava com alunos diagnosticados com TEA no contexto do Atendimento Educacional Especializado (AEE). O programa, conduzido pela pesquisadora, habilitada em Educação Especial, teve duração de 5 meses e envolveu, além da docente, professores regentes e profissionais de apoio/estagiários. Os resultados da pesquisa indicaram aumento do senso de auto eficácia docente ao término do programa. Dados de follow-up revelaram manutenção desse padrão de resposta 5 meses após a conclusão do estudo. 
http://dx.doi.org/10.5902/1984686X48492

Os estudos acima referidos salientam os resultados promissores da Consultoria Colaborativa no contexto da Educação Infantil, envolvendo educandos com TEA. Nessa perspectiva, o objetivo do presente estudo é avaliar os efeitos de um programa de Consultoria Colaborativa, a cargo de uma pedagoga, nas práticas de ensino adotadas por uma professora da Educação Infantil, que atendia um aluno diagnosticado com TEA. Dois objetivos específicos são destacados nessa pesquisa. O primeiro objetivo é avaliar os efeitos da capacitação no nível de mediação da docente, submetida à Escala de Avaliação da Experiência de Aprendizagem Mediada (EAM; LIDZ, 2003). O segundo consiste em identificar os efeitos da prática interventiva da professora, na participação do aluno com TEA durante as atividades propostas em sala de aula.

A prática interventiva descrita nesse artigo gera contribuições à literatura vigente sobre modelos de formação docente. O delineamento de pesquisa adotado oferece subsídios relevantes na condução de estudos, de natureza interventiva, em contextos naturalísticos.

\section{Método}

Participantes - participaram do estudo Gustavo, sua professora, sua cuidadora, a avó do aluno, uma pesquisadora e uma assistente de pesquisa. As características dos participantes e suas atribuições no estudo estão descritas no Quadro 1.

Quadro 1 - Identificação dos participantes

\begin{tabular}{|l|l|}
\hline Participante & Características/ Atribuições no estudo \\
\hline Gustavo & $\begin{array}{l}\text { Aluno diagnosticado com TEA, 4 anos/ aluno-alvo da } \\
\text { ação interventiva }\end{array}$ \\
\hline Professora & $\begin{array}{l}\text { Pedagoga, professora titular da turma/Professora-alvo } \\
\text { da ação interventiva, participou do curso de } \\
\text { capacitação }\end{array}$ \\
\hline Cuidadora & $\begin{array}{l}\text { Formanda em Pedagogia, cuidava de Gustavo na sala } \\
\text { de aula/ participou do curso de capacitação }\end{array}$ \\
\hline Avó & $\begin{array}{l}\text { Dona de casa, responsável por Gustavo/ auxiliou no } \\
\text { processo de avaliação do aluno e a identificar suas } \\
\text { potencialidades e dificuldades. }\end{array}$ \\
\hline Pesquisadora & $\begin{array}{l}\text { Pedagoga, mestranda em Educação/ atuou como } \\
\text { consultora }\end{array}$ \\
\hline $\begin{array}{l}\text { Assistente de } \\
\text { pesquisa }\end{array}$ & $\begin{array}{l}\text { Formanda em Pedagogia/ atuou como 1ํ juiz na } \\
\text { análise dos dados quantitativos do estudo }\end{array}$ \\
\hline
\end{tabular}

Fonte: Elaborado pelas autoras (2020) 
http://dx.doi.org/10.5902/1984686X48492

Delineamento de pesquisa - a presente investigação adotou delineamento multimétodo, envolvendo a coleta, análise e integração de dados de natureza qualitativa e quantitativa em um único estudo (CRESWELL, 2007). Procedimentos concomitantes de pesquisa, derivados da pesquisa-ação e da pesquisa quase experimental intrassujeito foram utilizados. Para a pesquisa-ação foi empregado um delineamento de pesquisa, de base empírica, implicando em ação ou resolução de um problema coletivo no qual os participantes, incluindo-se o pesquisador, encontram-se diretamente envolvidos de modo cooperativo ou participativo (THIOLLENT, 2009). A adoção dessa metodologia é justificada pela natureza colaborativa da consultoria proposta (ação interventiva), cujo objetivo é o aprimoramento da prática de ensino (problema).

Para proceder à análise dos efeitos da ação empreendida, recorreu-se ao delineamento de pesquisa quase experimental intrassujeito (GAST; LEDFORD, 2014), implementado em duas etapas distintas, compondo dois conjuntos de variáveis. Na primeira etapa foram avaliados os efeitos do programa de capacitação, no comportamento mediador da professora. Em seguida, foram avaliados os efeitos do comportamento mediador da docente na participação do aluno nas atividades escolares. O programa de capacitação constou de 16 encontros formativos, os quais serão descritos na seção de procedimentos.

O comportamento mediador da docente foi avaliado por meio da Escala de Avaliação da Experiência de Aprendizagem Mediada (EAM; LIDZ, 2003), apresentada na seção de instrumentos desse manuscrito. Os dados quantitativos produzidos pela pontuação da escala foram extraídos das sessões videografadas tanto nas fases de linha de base quanto nas de intervenção.

A avaliação do nível de participação do aluno, nas atividades escolares, consistia na observação e registro de comportamentos apropriados, emitidos pelo educando, no cumprimento de rotinas propostas pelos docentes (PEREIRA; NUNES, 2018). Dentre os comportamentos apropriados, que configuravam a participação do aluno constavam sentarse junto aos demais colegas, atender aos comandos da professora, esperar a vez e dirigir o foco de atenção ao interlocutor. Esses dados, de natureza qualitativa, derivam de registros fotográficos e do diário de campo da consultora.

A Figura 1 apresenta as variáveis da pesquisa nas duas etapas do estudo. 
http://dx.doi.org/10.5902/1984686X48492

Figura 1 - Variáveis da pesquisa nas duas etapas do estudo

Etapa 1

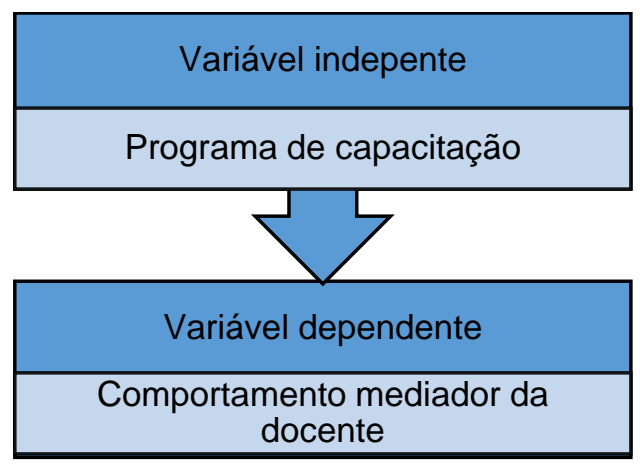

Etapa 2

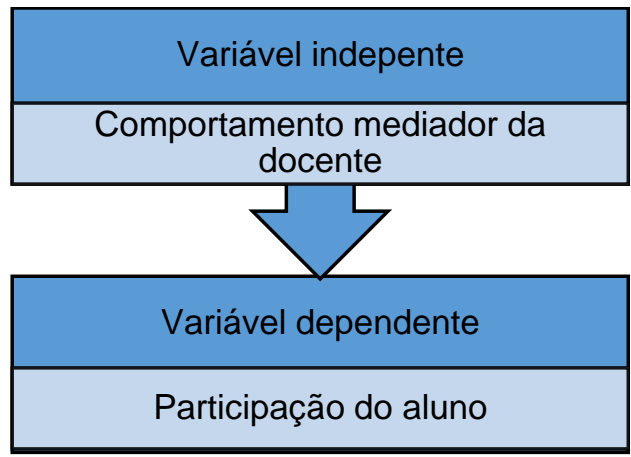

Fonte: Elaborado pelas autoras (2020)

Local - a pesquisa foi conduzida em uma turma regular da Educação Infantil, durante o turno vespertino, em escola da rede pública, localizada no município de Tenente Laurentino Cruz, no Estado do Rio Grande do Norte.

Instrumentos - foram utilizados dois roteiros de entrevista, o Child Autism Rating Scale (CARS; PEREIRA, 2007), um diário de campo e a EAM (LIDZ, 2003), adaptada por Macêdo (2015). O primeiro roteiro de entrevista, destinado à professora, continha perguntas voltadas à formação docente, percepção/concepções sobre o modelo da educação inclusiva, compreensão da sintomatologia do TEA e adaptações curriculares. O segundo, proposto à avó do estudante, incluía questões que tratavam das potencialidades e déficits de Gustavo.

A escala CARS (PEREIRA, 2007) foi utilizada para avaliar o grau de severidade do autismo da criança pesquisada. Foi aplicada em colaboração com professora e a avó, no decorrer da fase de pré-linha de base.

No diário de campo foram registradas as impressões da consultora, no decorrer de todo o trabalho de pesquisa.

Por fim, foi utilizada a EAM² (LIDZ, 2003), instrumento desenvolvido por Carol Lidz, fundamentado na Teoria da Experiência da Aprendizagem Mediada de Feurnstein (1990; apud LIDZ, 2003). Essa escala tem sido empregada em estudos nacionais e internacionais envolvendo populações com deficiência, incluindo educandos com TEA (NASCIMENTO, 2012; MACÊDO; NUNES, 2016). No presente estudo, foi utilizada uma adaptação da escala traduzida por Macêdo (2015). 
http://dx.doi.org/10.5902/1984686X48492

Materiais - Os materiais incluíram notebook, câmera filmadora, gravador de voz digital, material escolar (tesoura, cola, EVA, papeis, lápis coloridos etc.), livros infantis e textos científicos que versavam sobre as temáticas abordadas na capacitação.

Procedimentos - Após aprovação pelo comitê de ética, o estudo, realizado de maio a novembro de 2018, foi dividido em seis etapas:

Capacitação da assistente da pesquisa - a assistente foi capacitada, pela consultora, a utilizar a escala EAM (LIDZ, 2003). Nesse processo, foram realizadas análises de segmentos videografados de Gustavo com a professora. Inicialmente, a dupla pontuou a escala de forma coletiva e, posteriormente, de maneira independente. A capacitação foi finalizada quando o índice de concordância entre os observadores, ou seja, a consultora e a assistente de pesquisa, atingiu a marca superior a $75 \%$, em três sessões consecutivas. Vale destacar que as sessões utilizadas no treinamento foram descartadas, não sendo consideradas como dados do estudo.

Pré-linha de base - conduzidas as entrevistas com a professora e a avó de Gustavo, a aplicação da CARS (PEREIRA, 2007) e observações in loco. Adicionalmente, a professora identificou três rotinas as quais suscitavam maior dificuldade de engajamento do aluno. Essas rotinas, definidas como rotina inicial, atividade de contação de história e atividade acadêmica, se tornariam foco da ação interventiva.

Linha de Base - ocorreram, durante 20 dias, nove (09) registros videográficos das três rotinas alvo, identificadas na etapa anterior. Nessa fase, a consultora se limitou a proceder os registros, sem interferir na prática da docente. Três classes de comportamento foram avaliadas a) o nível de mediação da professora em interação com Gustavo (avaliado pela escala EAM); b) os tipos de atividades pedagógicas propostas e c) a participação do aluno nas atividades, conforme avaliado através dos registros fotográficos e diário de campo. Vale destacar que a duração média de cada uma dessas rotinas era de 10 a 15 minutos. Para a pontuação da EAM foram considerados os primeiros 5 minutos das atividades realizadas, de forma a garantir a uniformidade no tempo de duração das sessões.

Programa de capacitação - Com base nas demandas levantadas pela professora e pela consultora, foi elaborado um programa de capacitação docente. No total ocorreram 16 encontros formativos, com duas horas de duração, envolvendo a consultora, a professora e a cuidadora. Os conteúdos abordados no curso, com duração de 4 meses, incluíram a sintomatologia do TEA e práticas de ensino adotadas na Educação Infantil. Para a identificação das práticas foram considerados, inicialmente, os objetivos de aprendizagem 
http://dx.doi.org/10.5902/1984686X48492

e desenvolvimento descritos na Base Comum Curricular da Educação Infantil (BNCC-EI, BRASIL, 2018). A partir desse conteúdo, foram destacadas práticas que poderiam favorecer a participação do aluno nas rotinas que seriam foco da ação interventiva. Dentre elas, alternativas para a estruturação da rotina inicial, o uso de recursos visuais em atividades de contação de história, a adoção de materiais concretos em tarefas envolvendo quantificação e o uso da comunicação alternativa e ampliada. No processo formativo foram realizadas leituras de textos, apreciação de vídeos sobre o TEA e a construção de materiais didáticos. Adicionalmente, as rotinas videografadas na linha de base foram apresentadas à professora que, em colaboração com a consultora e a cuidadora, identificou aspectos positivos e negativos de interação. Esse último procedimento, denominado de autoscopia, se constitui em uma técnica de autoavaliação, tipicamente adotada na formação inicial e continuada de professores (NUNES, et al, 2020).

Intervenção - caracterizou-se pela implementação das práticas discutidas no decorrer das sessões de capacitação. Nessa fase, foram contabilizadas 27 sessões videografadas (09 de rotina inicial, 10 de atividades acadêmicas e 08 de sessão de história). O padrão de mediação da professora foi avaliado por meio da escala EAM (LIDZ, 2003). Assim como na fase de linha de base, foram pontuados os primeiros 5 minutos de interação da docente com a criança.

Validade social - essa etapa teve como propósito avaliar a percepção dos consultados sobre os efeitos da consultoria. Esses dados foram produzidos por meio de entrevista com a professora e a cuidadora e relato espontâneo da professora do Atendimento Educacional Especializado (AEE), que convivia com Gustavo, mas não participou do programa de Consultoria.

Índice de fidedignidade - para assegurar a fidedignidade dos dados, uma avaliação de concordância entre os observadores foi realizada. A assistente de pesquisa, atuando como $1^{\circ}$ juiz do estudo, pontuou a escala EAM nas sessões de linha de base e de intervenção. Vinte e cinco por cento dessas sessões foram avaliadas pela primeira autora, correspondendo a 3 sessões de linha de base e 7 sessões de intervenção. $O$ índice de concordância foi calculado a partir da fórmula proposta por Fagundes (2006). A percentagem média de concordância entre os observadores foi de $87 \%$ ( $80 \%$ - 100\%).

Análise de dados - Os instrumentos de pesquisa empregados nesse estudo produziram dois tipos de registros. O primeiro, de natureza quantitativa, foi calculado por meio da EAM. Os resultados produzidos por essa escala, registrados em frequência, foram 
http://dx.doi.org/10.5902/1984686X48492

plotados em gráficos e posteriormente analisadas com técnica de inspeção visual (GAST E LADFORD, 2014). O segundo foram os registros fotográficos das produções acadêmicas de Gustavo, assim como cenas que retratavam suas interações com a professora, a cuidadora e colegas na escola. O registro fotográfico, comumente adotado em pesquisas de natureza qualitativa, é artifício que permite ao leitor visualizar a realidade experenciada pelo pesquisador (CRESWELL, 2007).

\section{Resultados e discussão}

Os resultados do presente estudo são apresentados em três seções, considerandose os dados que caracterizam o participante, as rotinas escolares investigadas e registros de validade social da pesquisa.

\section{Caracterização do aluno}

Os dados dessa seção foram produzidos a partir de dados observacionais, avaliação da escala CARS (PEREIRA, 2007) e entrevista realizada com a avó, a professora e a cuidadora. De acordo com esses registros, Gustavo apresentava autismo grave (45 pontos), avaliado pela escala CARS (PEREIRA, 2007), residia com os avós e frequentava, há 4 anos, a escola na qual o estudo foi desenvolvido. Tanto no contexto da casa, quanto da escola, o menino demonstrava indiferença à presença de outras pessoas, permanecendo, na maior parte do tempo, isolado, engajado em brincadeiras estereotipadas ou em movimentos repetitivos. Não se comunicava verbalmente e demonstrava dificuldades em se fazer compreendido de forma não verbal. Emitia, por vezes, gritos estridentes quando desejava auxílio. Quando contrariado, constantemente, exibia condutas de autoagressão. Nessas ocasiões, tipicamente beliscava o corpo ou batia intensamente a cabeça contra a parede, além de lançar objetos. Em casa, segundo a avó, gostava de assistir desenhos animados na televisão. Na escola, conforme depoimento das demais entrevistadas, gostava de empilhar ou enfileirar brinquedos, móveis ou outros utensílios.

\section{Rotinas escolares}

Rotina Inicial - A rotina inicial era o momento em que a turma se agrupava no chão, em formato de círculo e a professora anunciava a rotina do dia. Nesses episódios, com duração de 10-15 minutos, a professora direcionava o roteiro, que tipicamente incluía, a chamada, a escolha do ajudante do dia, apresentação das atividades a serem realizadas, 
além de músicas e orações. A Figura 2 abaixo ilustra o nível de mediação da professora, durante a rotina inicial, com Gustavo.

Figura 2 - Nível de mediação de professora com Gustavo durante rotina inicial

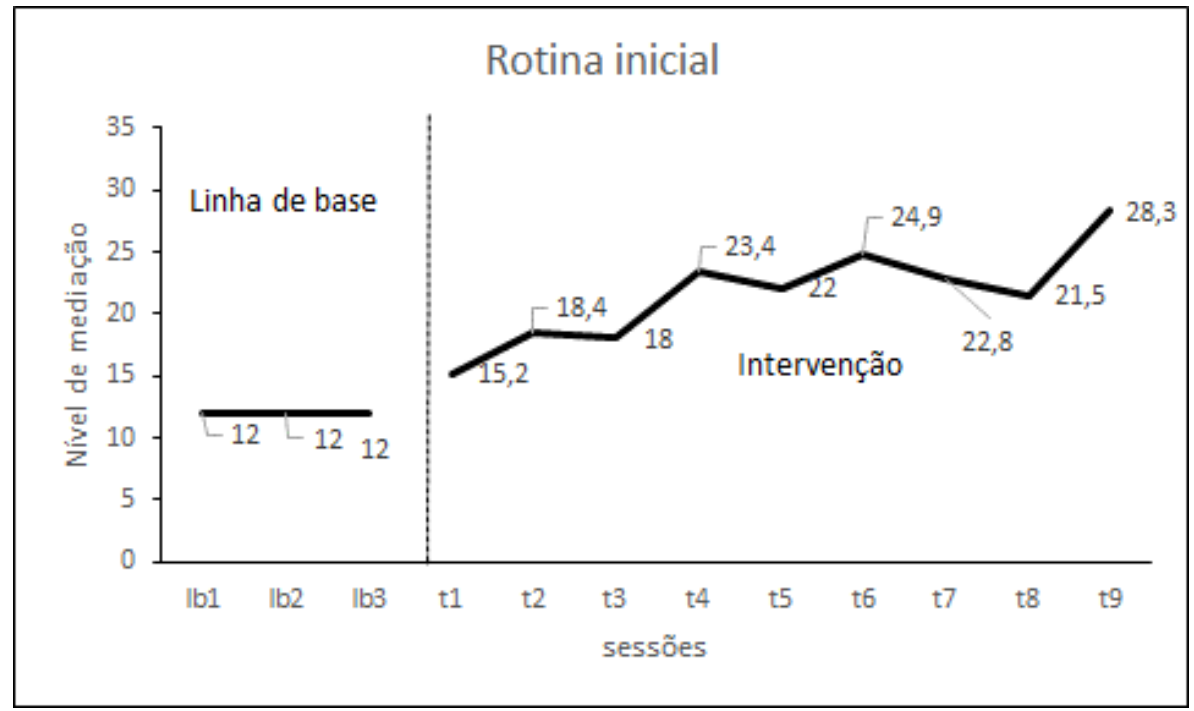

Fonte: Elaborado pelas autoras (2019).

Os registros de linha de base da figura acima sugerem que a professora não interagia com Gustavo no cotidiano de sala de aula. Isso é evidenciado pela pontuação mínima da escala, de 12 pontos. Na rotina inicial, o aluno tipicamente permanecia em um canto da sala, engajado em atividades paralelas, enquanto os demais colegas interagiam com a professora. A figura 3 ilustra esse comportamento. O menino brinca com massa de modelar, na segunda sessão de linha de base, enquanto os demais alunos estão na roda, com a professora.

Figura 3 - Gustavo na $2^{a}$ sessão de linha de base da rotina inicial

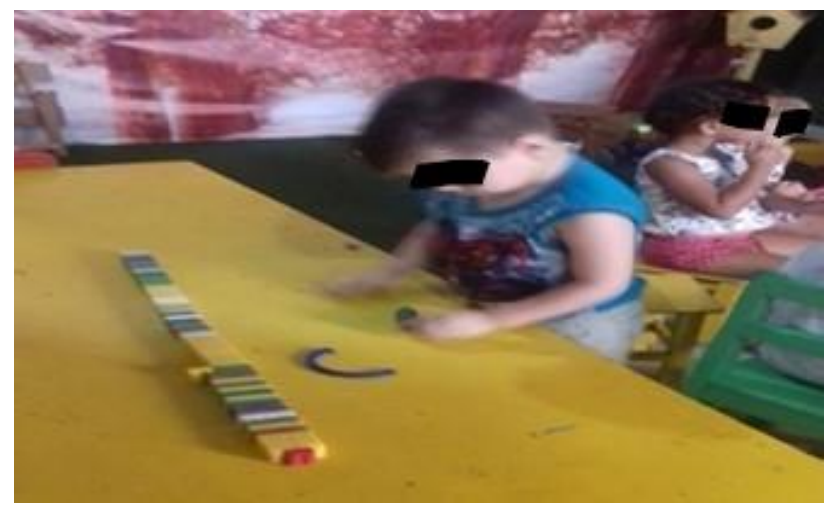

Fonte: Arquivo das autoras (2019). 
http://dx.doi.org/10.5902/1984686X48492

A limitada interação da professora com o aluno pode ser atribuída à sua falta de conhecimento sobre o TEA, como revelou no seguinte segmento, durante entrevista com a consultora:

eu nunca fiz nenhum curso sobre a inclusão, o autismo para mim é novo. Eu nunca tinha tido contato com uma criança autista, eu já tinha visto em alguns programas de TV. Já faz 15 anos que sou professora do Ensino Infantil e eu nunca tinha tido essa experiência (Professora, Diário de campo, 30/04/2018).

O desconhecimento a respeito do TEA, evidenciado na fala da professora, é congruente aos achados da literatura. De fato, diversos são os estudos que revelam que os professores do Ensino Infantil se sentem despreparados e incapacitados para atender às demandas educacionais de crianças com autismo (CASTRO; GIFONE, 2017; FAVORETTO; LAMÔNICA, 2014; LUZ; LIRA; GOMES, 2017; FERREIRA, 2017; SANINI; BOSA, 2015; SCHMIDT et al., 2016).

Aliado às lacunas formativas, a professora atribuía à cuidadora a tarefa de educar o aluno, conforme destacado no seguinte trecho:

(...) no planejamento, a gente nunca parou para pensar sobre o aluno com autismo. O planejamento direcionado a ele não acontece, fica a critério da cuidadora procurar alguma coisa pra fazer com o aluno. A gente não tá sabendo o que fazer com essa criança, porque não temos apoio, não tem material adequado, trabalhamos com poucos recursos pedagógicos, então, a gente quer uma luz pra ajudar (Professora, Diário de campo, 30/04/2018).

A designação de um cuidador como agente responsável pela educação do aluno com TEA é bem documentada em pesquisas nacionais. Estudos registram que esse profissional, denominado de mediador, auxiliar da vida diária ou monitor, tem assumido funções assistencialistas e pedagógicas, dentro e fora da sala de aula (ALVES, GUARESCHI E NAUJORKS, 2017; CARVALHO E NASCIMENTO, 2015; GOMES; MENDES, 2010; LIMA E LAPLANE,2016; TOGASHI E WALTER, 2016; BERTAZZO, PEREIRA E SCHMIDT, 2016).

Durante o programa de capacitação foram identificadas estratégias que poderiam favorecer a participação de Gustavo na rotina inicial. Na hora da chegada, momento que antecedia essa atividade, a professora passou a receber o aluno-alvo na porta da sala rotina que anteriormente cabia à cuidadora. Essa prática objetivava ampliar o vínculo da professora com ele próprio, considerando que grande parte das suas interações se limitava à auxiliar. 
Em seguida, a professora instruía as crianças a chamarem o colega a se sentar junto ao grupo. O chão, conforme observado na Figura 4, foi substituído pelo uso de cadeiras. Essa mudança pareceu favorecer a compreensão do aluno onde deveria se acomodar. Pesquisas sobre o Ensino Estruturado ${ }^{3}$ revelam que a organização do ambiente físico propicia a participação do aluno com TEA em atividades escolares (MESIBOV; SHEA E SCHOPLER, 2006; KLUTH, 2010).

\section{Figura 4 - Gustavo durante rotina inicial (4로 sessão de intervenção)}

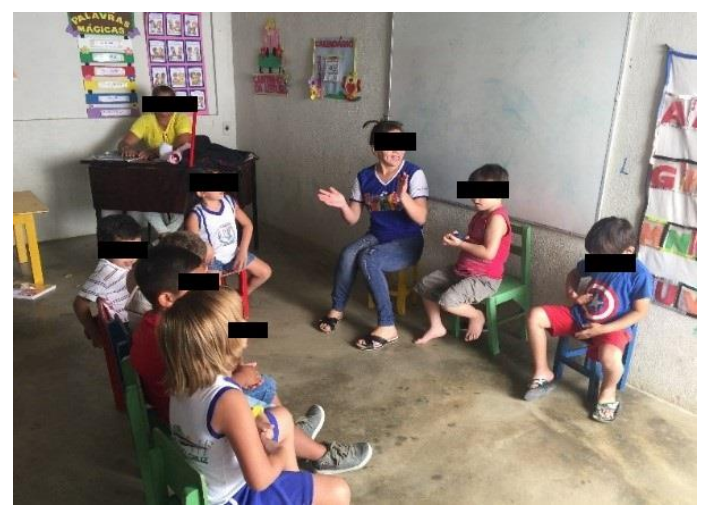

Fonte: Arquivo dos autores (2019).

$\mathrm{Na}$ figura 4, a professora se senta ao lado de Gustavo, posicionado à sua esquerda. A cuidadora, alocada em uma mesa, ao fundo da sala, foi instruída a auxiliar o aluno apenas quando este falhava em se manter engajado nas tarefas propostas. Essa orientação teve como base resultados de pesquisas que registram a importância de atribuir, ao profissional de apoio, papel de "coadjuvante" ou de suporte ao professor regente, que deve protagonizar o ensino (PEREIRA, 2019; TEIXEIRA E GANDA, 2019). Essa prática minimiza a estigmatização e a segregação dos alunos com TEA, inseridos em classes regulares (PURIFICAÇÃO et al., 2016; LIMA; LAPLANE, 2016).

Para favorecer a permanência de Gustavo na rotina inicial, a professora incluiu atividades de seu interesse. Assim, passou a adotar músicas que chamassem a sua atenção. Na figura 4 acima, o grupo canta a música "Quem veio hoje, qual é o seu nome?". O objetivo era a socialização das crianças que participavam da dinâmica e identificação da letra inicial do nome de cada aluno.

Atividades acadêmicas/escolares - No presente estudo as atividades acadêmicas foram definidas como tarefas de matemática, português, ciências e artes, coordenadas pela professora. Nessa rotina, as crianças tipicamente sentavam-se juntas à mesa para realizar as tarefas. Registros de diário de campo revelaram que, antes da intervenção, Gustavo não 
http://dx.doi.org/10.5902/1984686X48492

participava dessa atividade. O aluno permanecia afastado do grupo, supervisionado pela cuidadora, engajado em jogos de encaixe ou empilhando cadeiras. A ausência de interação é observada na fase de linha de base, respectivamente, na realização de atividades de português, artes e matemática.

Figura 5 - Nível de mediação da professora com Gustavo durante atividade acadêmica

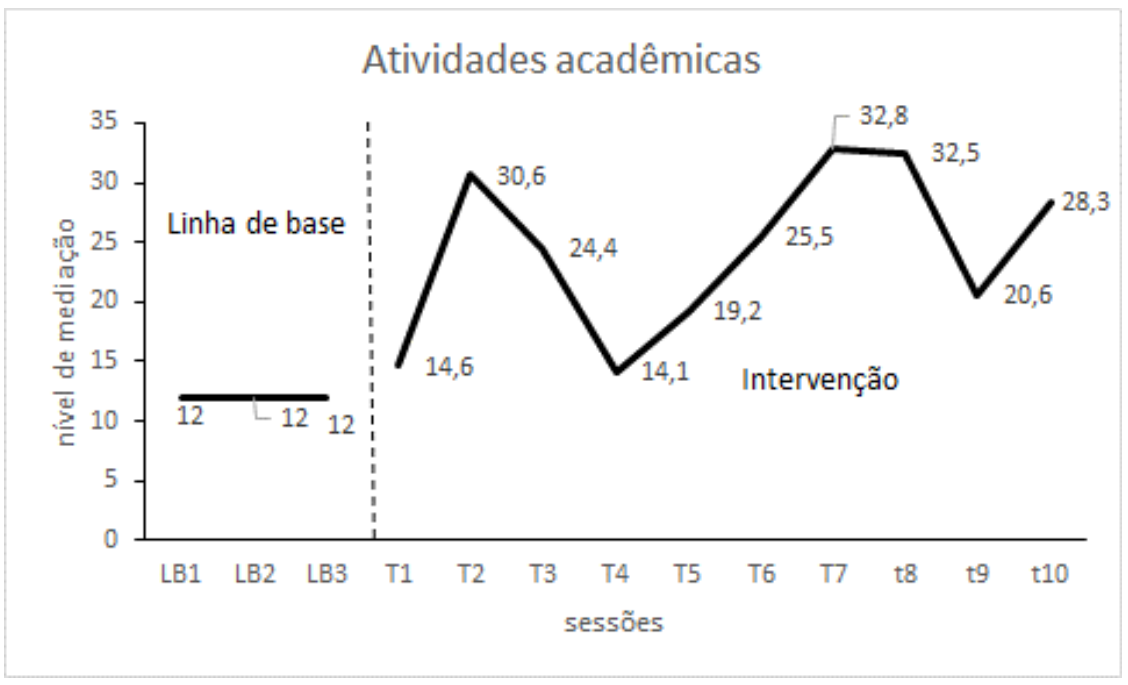

Fonte: Elaborado pelas autoras (2019).

O não envolvimento do aluno nas tarefas pode ser atribuída, dentre outros motivos, à falta de formação docente e carência de orientações provindas da própria escola. Essa visão é exposta na conversa da professora com a consultora, durante a capacitação:

a gente não tem estrutura pedagógica, não sabe nem o que fazer com essa criança. Durante esses dois para três meses de ensino, a gente não adequou e nem adaptou com a coordenadora nada diferente pra ele. Ele chega na sala, a gente tenta acalmá-lo, dá um brinquedo, um jogo, mas, como fazer a tarefa específica para o aluno com autismo, nunca existiu essa conversa, nem essa atitude (Professora, Diário de campo, 30/04/2018).

Na concepção da docente, o educando com TEA precisaria, em todas as instâncias, executar tarefas diferenciadas. Essa ideia é consonante com outras pesquisas, que salientam concepções errôneas de professores sobre as características de aprendizagem de educandos com autismo (CAMARGO; BOSA, 2009; SCHMIDT et al.., 2016; MARQUES; GIROTO, 2016).

Para desmistificar esse conceito, durante a capacitação, foram discutidas estratégias que poderiam ser benéficas para todos os alunos, incluindo Gustavo. Uma das práticas salientadas foi o uso de materiais concretos para desenvolver habilidades de relacionar os números às suas respectivas quantidades, objetivo curricular identificado na BNCC da 
Educação Infantil (BRASIL, 2018). Vale destacar que o uso de materiais concretos é recomendado não apenas para educandos com desenvolvimento típico, mas também para aqueles com diagnóstico de TEA (KLUTH, 2010; MARCHIORI, FRANÇA, 2018).

$\mathrm{Na}$ Figura 6, correspondentes à $7^{\mathrm{a}}$ sessão de intervenção, a professora realiza uma atividade sobre números e quantidades com Gustavo em projeto de matemática. O objetivo da tarefa era agrupar e associar a quantidade ao numeral correspondente.

Figura 6 - Professora e Gustavo durante atividade de matemática (7ª sessão de intervenção)

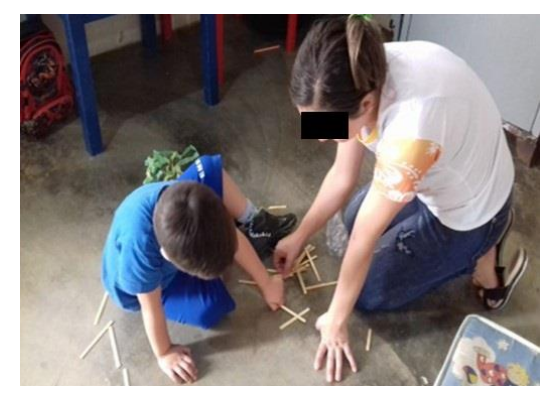

Fonte: Arquivo das autoras (2019).

Contação de histórias - As atividades de contação de histórias tipicamente ocorriam duas vezes por semana e eram lideradas pela professora. Nessas rotinas, a docente realizava leituras compartilhadas, chamando os alunos a se sentarem em suas cadeiras, ao seu redor, e contava verbalmente uma história.

Conforme observado na Figura 7 o nível de mediação da professora com Gustavo nessas rotinas era baixo durante o período de linha de base.

Figura 7 - Nível de mediação da professora com Gustavo durante rotina de contação de histórias

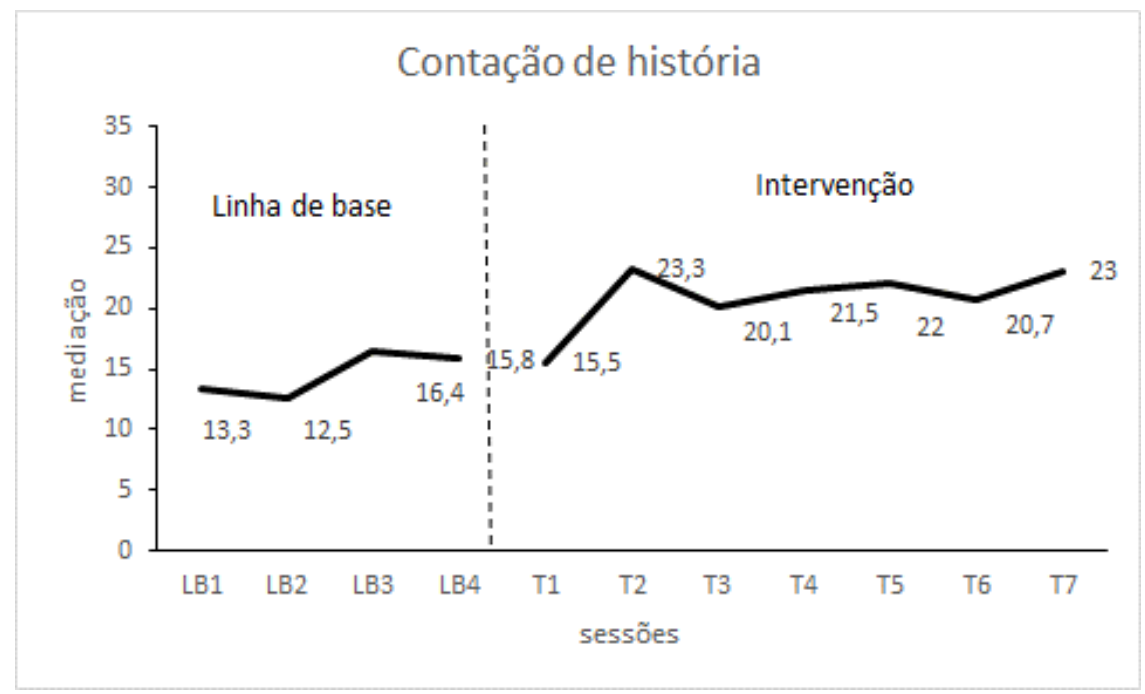

Fonte: Elaborado pelas autoras (2019). 
A docente raramente incluía Gustavo nessa rotina. Nesses momentos, o aluno era tipicamente conduzido, pela cuidadora, ao centro da roda, onde permanecia manipulando um objeto. Esse episódio é ilustrado na figura 8, onde Gustavo, deitado no centro do círculo, manuseia, de maneira estereotipada, um brinquedo. Registros de campo revelaram que a professora dirigia a fala aos alunos que estavam sentados ao seu redor, mas não interagia com Gustavo.

Figura 8 - Rotina de contação de história (1 ${ }^{a}$ sessão de linha de base)

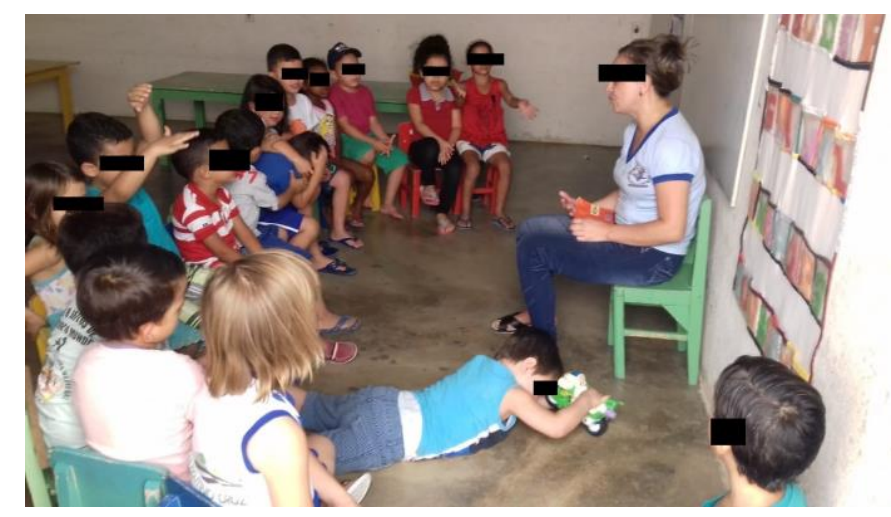

Fonte: Arquivo das autoras (2019).

A leitura compartilhada é considerada atividade de grande relevância para o desenvolvimento da linguagem e da comunicação de educandos com TEA. Estudos indicam que essa prática favorece o desenvolvimento da atenção compartilhada, amplia o vocabulário e estimula a comunicação desse alunado (FLEURY; SCHWARTZ, 2016; SOUZA; QUEIROZ; FLORES, 2017; WALTER; NUNES, 2020).

Com vistas a engajar Gustavo nessa rotina, a consultora sugeriu um plano de ação com três estratégias. Primeiramente, deveria antecipar o momento da história com a exposição do livro a ser trazido para a turma. Assim, deveria apresentar, antes da narrativa, os personagens, através de gestos e músicas. Nesse momento a professora chamaria todos os alunos, incluindo Gustavo, a sentar-se no círculo.

Em segundo lugar, a professora deveria suplementar as verbalizações com o uso de gestos e exibição das imagens do livro. O uso de recursos visuais associado à fala favorece a compreensão verbal de educandos com TEA (MESIBOV et al., 2006). Por fim, a docente foi aconselhada a fazer uma síntese da história por meio de música ou atividade interativa.

A participação nas rotinas de contação de histórias pareceu ter aguçado o interesse de Gustavo pela leitura. Registros fotográficos e de diário de campo revelaram busca espontânea pelos livros, conforme ilustrado na Figura 9. Nessa cena, registrada após a 
capacitação, o aluno, ao chegar na sala de aula, dirigiu-se à estante e pegou a obra "Mãenhê!", de Ilan Brenman (2012), que havia sido contada à turma na tarde anterior. Surpreendida com o comportamento do menino, que frequentemente buscava um brinquedo quando chegava na sala, a professora se aproximou de Gustavo e recontou a história.

Figura 9 - Gustavo e a professora leem o livro "Mãenhê!" ao lado de dois colegas de sala

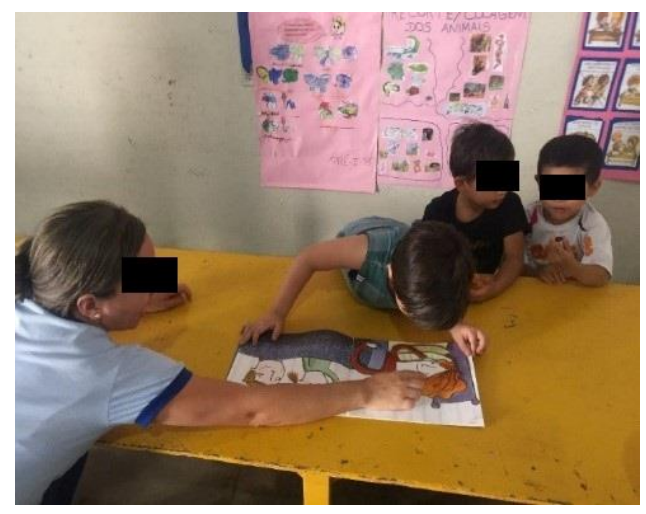

Fonte: Arquivo dos autores (2019).

\section{Validade social}

Por validade social compreende-se a avaliação dos resultados de uma prática interventiva por indivíduos impactados, de forma direta ou indireta, por seus efeitos. Ou seja, as pessoas diretamente envolvidas na pesquisa, assim como aquelas que experimentaram seus resultados de forma indireta (GAST;LEDFORD, 2014). No presente estudo, dados de validade social foram produzidos através de entrevistas conduzidas com a professora e a cuidadora, que estiveram diretamente implicadas no estudo. Adicionalmente, foi considerado, nesse registro, depoimento espontâneo proferido pela professora do AEE que, embora não tenha participado da Consultoria por incompatibilidade de tempo, conviveu com Gustavo durante a intervenção.

Ao término do projeto, ao ser questionada sobre o programa de consultoria, a professora respondeu: 
http://dx.doi.org/10.5902/1984686X48492

Esse curso pra mim foi de suma importância, tinha um aluno na minha sala com autismo, realmente ele tava lá, só que ele não tava incluso na sala. Ele estava mais com a cuidadora, mas ficava só por ficar.... Durante o curso a gente foi vendo, estudando maneiras de como ajudar essa criança interagir na sala, participar, a se envolver com a turma, a socializar. E, vimos também, coisas que ele possa evoluir, aprender de alguma forma para ser utilizado no seu cotidiano, na sua vida essa aprendizagem. E, fizemos oficinas aqui, duas oficinas maravilhosas com materiais para ser utilizado com o aluno autista, muita coisa: alfabeto, números, comunicação alternativa. Tudo o que a gente viu foi maravilhoso, para mim foi excelente. Antes, o que eu sabia sobre o autismo é o que eu ouvia falar, agora eu sei e vou saber trabalhar com um aluno com essa deficiência, vai me ajudar para minha vida toda, gostei demais!

(Professora, Entrevista, 21/11/18)

O relato acima revela que, a despeito da natureza colaborativa da proposta, a professora se referia ao programa como um "curso". Essa perspectiva pode ser atribuída a dois fatores. Primeiro, à ausência de formações prévias da docente, o que a fazia enfatizar o aspecto formativo da consultoria. Segundo, em contraposição ao modelo da consultoria, que pressupõe um enfoque igualitário entre consultor e consultado (MENDES et al., 2011; CANABARRO, 2018), a professora tendia a adotar uma posição passiva, aguardando continuamente instruções da pesquisadora sobre como proceder com o aluno.

Com a assiduidade dos encontros, foi observada postura proativa da docente, que passou a sugerir - embora de forma tímida, novas práticas e não apenas acatar as sugestões da consultora. Resultado consonante foi identificado no estudo de Canabarro (2018), envolvendo uma professora da Educação Especial que atuava no AEE e uma consultora. Nessa pesquisa, a autora revela que a "valorização e equivalência das competências e experiências" entre o consultor e consultado é adquirida com o tempo, na continuidade de encontros formativos.

Em consonância à docente, a cuidadora mostrou-se satisfeita com a intervenção, assim como destacou o aspecto formativo do programa. Essa perspectiva é revelada no seguinte fragmento:

Como cuidadora, não sabia como agir diante de um autista, eu sabia que tinha que pensar na aprendizagem dele, mas não sabia como agir. Eu só sabia mesmo cuidar. Então, através dessa intervenção e das oficinas que foi repassada pra gente, aprendi muita coisa, tive bastante ajuda da professora, pela intervenção, ela se esforçou o máximo em me ajudar e o que a gente aprendeu nessa intervenção foi colocar em prática. Adorei, e se fosse para fazer outra intervenção como essa, eu faria, porque é pensando no aluno e na aprendizagem dele que ele se desenvolveu bastante através dos trabalhos desenvolvidos que a gente, eu, como cuidadora, juntamente com a professora, colocamos em prática, essa formação vai me ajudar bastante daqui para frente, trabalhar com ele ou com outro autista.

(Cuidadora, Entrevista, 21/11/2018) 
http://dx.doi.org/10.5902/1984686X48492

O segmento inicial do relato da cuidadora sugere incertezas sobre o papel do cuidador, fenômeno identificado em outros estudos salientados nesse manuscrito (NUNES et al., 2013; ALVES et al.,2017; BERTAZZO et al., 2016). Em seu depoimento, a cuidadora enfatiza que, após a capacitação, passou a ponderar sobre aspectos relacionados à aprendizagem acadêmica do aluno, indo além dos seus cuidados. A possibilidade de atuar em parceria com a professora regente, destacado no depoimento, parece ter sido central nessa mudança de postura.

Ao término do programa, a consultora despediu-se da professora do $A E E$, por meio de aplicativo de mensagens visto que, por incompatibilidade de horários, não poderia encontrá-la pessoalmente. Em resposta a esse texto, ela replicou:

Desde já agradecer o trabalho que está sendo desenvolvido no município. Esse despertar que você veio dar na gente, nos profissionais. Foi muito importante essa conecção de escola, família. Os resultados de Gustavo é porque todos estão falando a mesma língua, né? Não só escola, mas família também! E, aí está o resultado dele, se desenvolvendo a cada dia e graças a você, que veio com esse trabalho para Tenente Laurentino para nos ajudar. Muitíssimo obrigada, viu?

(Depoimento da professora do AEE via aplicativo de mensagens, no dia 26/11/2018, grifo nosso).

\section{Considerações finais}

Em consonância com a literatura, os dados do presente estudo sugerem que a Consultoria Colaborativa é uma prática promissora a ser adotada no contexto da Educação Infantil. Os resultados dessa pesquisa apontam que, após a implementação do programa, foram registrados aumento na frequência de ocorrência de comportamentos mediadores da professora e mudanças qualitativas na participação do aluno-alvo nas atividades escolares. Ademais, os professores envolvidos, de forma direta e indireta, mostraram-se satisfeitos com a proposta, ressaltando, particularmente, sua importância na formação docente.

A despeito desses achados, é preciso ponderar sobre as limitações do estudo. Primeiro, vale destacar as limitações metodológicas do uso de delineamentos quaseexperimentais de pesquisa. Embora essa metodologia se adeque a contextos naturais, lacunas podem ser evidenciadas em termos de validade interna, fragilizando a relação funcional entre as variáveis delineadas. Futuras investigações devem, portanto, considerar o uso de metodologias experimentais mais robustas, como delineamentos de linha de base múltipla, onde o controle experimental é ampliado.

Em segundo lugar, por limitações do tempo, a consultora não pôde retornar à escola para avaliar se a professora deu prosseguimento às estratégias interventivas desenvolvidas 
http://dx.doi.org/10.5902/1984686X48492

durante a Consultoria. Como identificado no estudo de Olmedo e Walter (2015), com a saída do consultor, os professores podem não dar prosseguimento às práticas aprendidas, tornando ineficaz o programa colaborativo. Assim sendo, futuras investigações devem, como realizado no estudo de Canabarro (2018), conduzir sessões de follow-up.

O terceiro ponto destacado refere-se à identificação de medidas fidedignas para avaliar o nível de participação do aluno nas rotinas, além de dados de natureza qualitativa. Nessa perspectiva, seria relevante, complementar os registros fotográficos, com registros que contabilizam o tempo de permanência do educando nas tarefas escolares.

Diante das lacunas destacadas e do número reduzido de participantes nesta pesquisa, é necessária a condução de novos estudos envolvendo práticas colaborativas entre Educação Especial e ensino comum, com participantes diagnosticados com TEA.

\section{Referências}

ALVES, Marcia Doralina, GUARESHI, Taís; NAUJORKS, Maria Inês. Alunos com Autismo: um estudo dos tempos e dos espaços de escolarização. Revista pedagógica. Chapecó.v.19, n.40, p.262-285, jan/abr.2017.

AZEVEDO, Mariana Queiroz Orrico de; NUNES, Débora Regina de Paula. Que Sugerem as Pesquisas sobre os Métodos de Ensino para Alunos com Transtorno do Espectro Autista? Uma Revisão Integrativa da Literatura. Arquivos Analíticos de Políticas Educativas v. 26, n. 24, 2018. Disponível em. http://dx.doi.org/10.14507/epaa.26.3367. Acesso em: 10 jul. 2020.

BERTAZZO, Joíse; PEREIRA, Eliane; SCHMIDT, Carlo. O Acompanhante Escolar de Alunos com Autismo na Legislação Brasileira. In: ANAIS DO 7ํㅡ을 BRASILEIRO DE EDUCAçãO ESPECIAL, 2016, São Carlos. Anais eletrônicos... Campinas, Galoá, 2016. Disponível em: https://proceedings.science/cbee/cbee7/papers/oacompanhante-escolar-de-alunos-com-autismo-na-legislacao-brasileira. Acesso em: 11 jul. 2020.

BRASIL. Secretaria da Educação Básica. Base Nacional Comum Curricular. Brasília: Ministério da Educação, 2018. Disponível em: http://basenacionalcomum.mec.gov.br/. Acesso em: 11 jul. 2020.

CAMARGO, Síglia Pimentel Höher; BOSA, Cleonice Alves. Competência social, inclusão escolar e autismo: revisão crítica da literatura. Psicol. Soc., Florianópolis, v. 21, n. 1, p. 65-74, Apr. 2009. Disponível em: http://www.scielo.br/scielo.php?script=sci_arttext\&pid= S0102-71822009000100008\&lng=en\&nrm=iso. Acesso em 11 jul. 2020. https://doi.org/10.1590/S0102-71822009000100008. 
CANABARRO, Renata Corcini Carvalho. Consultoria Colaborativa: Influências na autoeficácia docente e no processo de inclusão de alunos com transtorno do espectro autista. 2018. 224 f. Tese (Doutorado) - Curso de Educação Especial, Universidade Federal de Santa Maria, Santa Maria, 2018.

CANABARRO, Renata Corcini Carvalho; TEIXEIRA, Maria Cristina Triguero Veloz; SCHMIDT, Carlo. Tradução e Adaptação Transcultural da Escala de Avaliação de Autoeficácia de Professores de Alunos com Autismo: Autism Self-Efficacy Scale for Teachers (Asset). Rev. bras. educ. Espec., Bauru, v. 24, n. 2, p. 229-246, Abr. 2018. Disponível em http://www.scielo.br/scielo.php?script=sci_arttext\&pid=S141365382018 000200229\&lng=en\&nrm=iso. Accesso em 11 jul. 2020. https://doi.org/10.1590/s141365382418000200006 .

CARVALHO, Brunna Estela e NASCIMENTO, Lilian Ferreira. O autista e sua inclusão nas escolas particulares da cidade de Teresina -PI. Revista Educação Especial. Santa Maria, v.28. n.53.p. 677-690. set/dez, 2015

CASTRO, Ana Cristina de; GIFFONI, Silvyo David Araújo. O conhecimento de docentes de educação infantil sobre o transtorno do espectro autístico. Rev. psicopedag., São Paulo , v. 34, n. 103, p. 98-106, 2017 . Disponível em:http://pepsic.bvsalud.org/scielo.php? script=sci_arttext\&pid=S0103-84862017000100010\&lng=pt\&nrm=iso. acessos em 22 jul. 2020.

CRESWELL, John W. Projeto de pesquisa: métodos qualitativo, quantitativo e misto / CRESWELL; John W. Tradução ROCHA, Luciana de Oliveira da Rocha. - 2. ed. - Porto Alegre: Artmed,2007.248 p.

FAGUNDES, Antônio. Descrição, definição e registro de comportamentos. São Paulo: Edicon, 2006.

FAVORETTO, Natalia Caroline; LAMÔNICA, Dionísia Aparecida Cusin. Conhecimentos e Necessidades dos Professores em Relação aos Transtornos do Espectro Autístico. Rev. Bras. Ed. Esp., Marília, v. 20, n. 1, p. 103-116, Jan.-Mar., 2014.

FERREIRA, Roberta Flávia Alves. Inclusão de crianças com transtorno do espectro autista, na educação infantil: o desafio da formação de professoras. 2017. 160 f. Tese (Doutorado) - Faculdade de Educação, Universidade Federal de Minas Gerais, Belo Horizonte, 2017.

FLEURY, Verónica; SCHWARTZ, llene. S. A modified dialogic reading intervention for preschool children with autism spectrum disorder. Topics in Early Childhood Special Education, v. 37, n. 1, p. 16-28, 2016.

FOLHA, Débora Ribeiro da Silva Campos; MONTEIRO, Gláucia de Souza. Terapia ocupacional na atenção primária à saúde do escolar visando a inclusão escolar de crianças com dificuldades de aprendizagem. Rev. Interinst. Bras. Ter. Ocup. Rio de Janeiro. v.1, n.2, p. 202-220, 2017. 
http://dx.doi.org/10.5902/1984686X48492

GAST, David; LEDFORD, Jennifer R, eds. Single case research methodology: Applications in special education and behavioral sciences. 2 ed. New York: Routledge, 2014.

GOMES, Camila Graciella Santos e MENDES, Enicéia Gonçalves.Escolarização inclusiva de alunos com autismo na rede municipal de ensino de Belo Horizonte. Revista Brasileira de Educação Especial.v.16 n.3. Marília. Set/dez. 2010.

KLUTH, Paula. You're going to love this kid! 2.ed. Baltimore: Paul H Brooks, 2010.

LIDZ, Carol. S. Early childhood assessment. 1.ed. New York: John Wiley \& Sons, 2003.

LIMA, Stéfanie Melo; LAPLANE, Adriana Lia Friszman de. Escolarização de Alunos com Autismo. Rev. Bras. Ed. Esp., Marília, v. 22, n. 2, p. 269-284, Abr.-Jun., 2016.

LUZ, Mariana Helena Silva da; LIRA, Adriana; GOMES, Candido Alberto. Narrativas sobre a inclusão de uma criança autista: desafios à prática docente. Educación, Lima, v.26, n.50, p. 123-142, mar. 2017.

MACÊDO, C. R. S. de. A criança com Transtorno do Espectro Autista (TEA) e o professor: uma proposta de intervenção baseada na Experiência de Aprendizagem Mediada (EAM). 2015. 163 f. Dissertação (Mestrado em Educação) UFRN, Natal, 2015.

MACÊDO, Cláudia Roberto Soares de; NUNES, Débora Regina de Paula; Aprendizagem mediada na escolarização de educandos com autismo. Revista Educação em Questão, Natal, v. 54, n. 42, p. 135-160, set./dez. 2016.

MAENNER, Matthew J.; SHAW, Kelly. A.; BAIO, Jon.; WASHINGTON, Anita.; PATRICK, Mart.; DIRIENZO, Monica.; CHRISTENSEN, Deborah.L.; WIGGINS, Lisa .D.;

PETTYGROVE, Sydney.; ANDREWS, Jennifer.G.; et al. Prevalence of Autism Spectrum Disorder Among Children Aged 8 Years-Autism and Developmental Disabilities

Monitoring Network, 11 Sites, United States, 2016. MMWR Surveill. Summ. v. 69, p.1-12, 2020.

MARCHIORI, Alexandre Freitas; FRANÇA, Carla de Almeida Aguiar. Práticas e articulações pedagógicas na educação infantil: contribuições ao processo de desenvolvimento de uma criança com autismo. Zero-a-Seis, Florianópolis, v. 20, n. 38, p. 488 - 513, out. 2018. ISSN 1980-4512. Disponível em: https://periodicos.ufsc.br/index.php /zeroseis/article/view/1980-4512.2018v20n38p488. Acesso em: 22 jul. 2020. doi:https://doi.org/10.5007/1980-4512.2018v20n38p488.

MARQUES, Jaqueline Belga; GIROTO, Claudia Regina Mosca. Trabalho docente com alunos público-alvo da educação especial na educação infantil. Revista Ibero-Americana de Estudos em Educação, [S.I.], p. 895-910, sep. 2016. ISSN 1982-5587. Disponível em: https://periodicos.fclar.unesp.br/iberoamericana/article/view/8933. Acesso em: 22 jul. 2020. doi:https://doi.org/10.21723/riaee.v11.esp2.p895-910. 
MENDES, Eniceia Gonçalves; ALMEIDA, Maria Amélia; TOYODA, Cristina Yoshie. Inclusão escolar pela via da colaboração entre educação especial e educação regular. Educar em Revista. Setor de Educação da Universidade Federal de Uberlândia (UFU), n. 41, p. 80-93, 2011. Disponível em: http://hdl.handle.net/11449/29852.

MESIBOV, Gary. B., SHEA, Victoria., \& SCHOPLER, Eric. The TEACCH approach to autism spectrum disorders. 1. ed. New York: Springer Science \& Business Media, 2006.

MICHELS, Maria Helena. O que há de novo na formação de professores para a Educação Especial? Revista Educação Especial, Santa Maria. v. 24, n. 40, p, 219-232, 2011.

NASCIMENTO, Renata. Cristina. de L. C. B. Práticas Pedagógicas de Professores de 1 Ano do Ensino Fundamental: concepções sobre a inclusão de crianças de seis anos, sua mediação e avaliação de aprendizagem. 2012. 129 f. Dissertação (Mestrado em Educação). Cáceres, 2012.

NEVES, Anderson Jonas das; ANTONELLI, Carolina de Santi; SILVA, Mariana Girotto Carvalho da. CAPELLINI, Vera Lúcia Messias Fialho. Escolarização formal e dimensões curriculares para alunos com autismo: o estado de arte da produção acadêmica brasileira. Educação em Revista. Belo Horizonte v.30, n.2, p.43-70, Abril-Junho 2014.

NOZI, Gislaine Semcovici; VITALIANO, Celia Regina. Saberes necessários aos professores para promover a inclusão de alunos com necessidades Educacionais Especiais. Rev. Educ. Espec., Santa Maria, v. 25, n. 43, p. 333-348, maio/ago. 2012. Disponível em: http://www.ufsm.br/revistaeducacaoespecial.

NUNES, Débora R. P.; AZEVEDO, Mariana Q. O.; SCHMIDT, Carlo. Inclusão educacional de pessoas com Autismo no Brasil: uma revisão da literatura. Revista Educação Especial, Santa Maria, v. 26, n. 47, p. 557-572, set./dez. 2013.

NUNES, Débora R. P.; SCHMIDT, Carlo. Educação especial e autismo: das práticas baseadas em evidências à escola. Cad. Pesqui., São Paulo, v. 49, n. 173, p. 84-103, Set. 2019

NUNES, Leila R. P. ; SILVA, Stefhanny. P. N. ; Nunes, Débora R.P. ; SCHIRMER, Carolina R. . Técnicas e procedimentos de autoscopia na formação inicial e continuada do professor reflexivo: revisão descritiva da literatura. In: Leila Regina de Paula Nunes. (Org.). Autoscopia: uma ação reflexiva sobre a prática docente. 1ed.Rio de Janeiro: EDUERJ, 2020, v. 1, p. 13-42.

OLMEDO, Patrícia Blasquez. Sem comunicação, há inclusão? Formação de educadores em Comunicação Alternativa para crianças com autismo. 2015. $204 \mathrm{f}$. Dissertação (Mestrado em Educação) - Faculdade de Educação, Universidade do Estado do Rio de Janeiro, Rio de Janeiro, 2015.

PEREIRA, Alessandra Marques. Autismo Infantil: Tradução e Validação da CARS (Childhood Autism Rating Scale) para uso no Brasil. 181 f. Dissertação (Mestrado em Pediatria). Universidade Federal do Rio Grande do Sul, Porto Alegre, RS, 2007. 
PEREIRA, Débora Mara; NUNES, Débora. R. P. Diretrizes para a elaboração do PEI como instrumento de avaliação para educando com autismo: um estudo interventivo. Revista Educação Especial, Santa Maria. v. 31. n. 63, out./dez. p. 939-960, 2018.

PEREIRA, Luciane Clementino. Formação do profissional de apoio educacional para o atendimento de crianças com autismo no ensino regular. 2019. 83

f. Dissertação (Mestrado em Educação) - Faculdade de Educação, Universidade Federal da Grande Dourados, Dourados, MS, 2019.

PURIFICAÇÃO, Marcelo Máximo; TEPERINO, Ana Paula Pertussati; TACELI, Izabel Cristina; PESSOA, Maria Teresa Ribeiro. O brincar como elemento de inclusão escolar de crianças caracterizadas com transtornos do espectro autista (TEA). Interfaces da Educ., Paranaíba, v.7, n.19, p.48-65, 2016.

RIBEIRO, Daniela Mendonça; MELO, Nínive Rodrigues Cavalcanti de; SELLA, Ana Carolina. A inclusão de estudantes com autismo na rede municipal de ensino de Maceió. Revista Educação Especial, Santa Maria v. 30 n. 58, p. 425-440, 2017.

RIO GRANDO DO NORTE. SECRETARIA DE ESTADO DA EDUCACÃO. (Ed.). Monitoramento da Educação Secretaria de Estado de Educação do Rio Grande do Norte: Relatório de Estudantes com NEE - Analítico. 2020. Disponível em: https://sigeduc.rn.gov.br/sigeduc/public/transparencia/pages/consulta/relatorio_estudantes /relEstudantesNEEAnalitico.jsf. Acesso em: 26 jan. 2020.

SANINI, Cláudia; BOSA, Cleonice Alves. Autismo e inclusão na educação infantil: Crenças e autoeficácia da educadora. Estudos de Psicologia, Natal, v. 3, n. 20, p. 173183, julho/set., 2015.

SANT'ANNA, Maria Madalena Moraes; MANZINI, Eduardo José. Identificação de necessidades iniciais para formação continuada de professores da educação infantil para o público-alvo da educação especial. Revista Educação Especial em Debate, Vitória, v 2, n. 5 p. 29-45, jan./jun., 2018.

SCHMIDT, Carlo, NUNES, Débora R.P.; PEREIRA, Débora Mara; OLIVEIRA, Vivian Fátima de; NUERNBERG, Adriano Henrique; KUBASKI, Cristiane. Inclusão escolar e autismo: uma análise da percepção docente e práticas pedagógicas. Revista Psicologia: Teoria e Prática, São Paulo, v.1 n.18, p. 222-235, 2016.

SOUZA, Victor Guevara Loyola de; QUEIROZ, Lara Rodrigues; FLORES, Eileen Pfeiffer. Leitura dialógica adaptada para uma criança com transtorno do espectro autista: um estudo preliminar. Cadernos de Pós-Graduação em Distúrbios do Desenvolvimento, São Paulo, v.17, n.1, p. 87-99, 2017.

TEIXEIRA, M. C. S.; GANDA, D. R. INCLUSÃO E AUTISMO: relato de caso sobre o trabalho com uma criança na educação infantil. Psicologia e Saúde em debate, Patos de Minas, v. 5, n. 2, p. 125-135, dez. 2019. 
THIOLLENT, Michel. Metodologia da pesquisa-ação. São Paulo: Cortez, 2009.

TOGASHI, Cláudia Miharu; WALTER, Cátia Crivelenti de Figueiredo. As Contribuições do Uso da Comunicação Alternativa no Processo de Inclusão Escolar de um Aluno com Transtorno do Espectro do Autismo. Rev. bras. educ. espec. Marília, v. 22, n. 3, p. 351366, set. 2016.

WALTER, Elizabeth Cynthia; NUNES, Débora Regina de Paula. Avaliação da eficácia de um programa de compreensão da leitura oral dialógica por criança com autismo. ETDEducação Temática Digital Campinas, v.22 n.1 p.27-49 jan./mar. 2020.

\section{Notas}

${ }^{1}$ Por autoeficácia docente compreende-se a "crença do professor em sua capacidade para desenvolver as ações pedagógicas que conduzam aos resultados desejados" (CANABARRO, TEIXEIRA, SCHMIDT, 2018).

${ }^{2}$ A EAM avalia 12 componentes mediadores que favorecem a aprendizagem. Eles incluem significação, transcendência, atenção partilhada, experiência partilhada, regulação na tarefa, elogio/feedback, desafio, envolvimento afetivo, modificação, responsividade contingente e diferenciação psicológica. Trinta e quatro afirmativas/asserções (itens), pontuadas por uma escala Likert (de 1 a 4 pontos) são utilizadas para avaliar esses componentes. Após a pontuação, os itens são agrupados em 12 blocos, correspondente aos 12 componentes mediadores. Vale destacar que o número de itens por componente varia de 1 a 8 . Assim, o componente de "elogio/feedback" é avaliado por 2 itens, ao passo que "intencionalidade", por 3. Após o agrupamento, é calculada a pontuação média de cada componente (soma das pontuações dos itens dividido pelo total de itens contemplados no componente). A pontuação máxima dos 12 componentes é de 48 pontos (4 pontos x 12) e a mínima de 12 pontos (1 ponto x 12), identificando carência de interação. Com base nesse cálculo, quanto mais alta a pontuação, melhor o nível de mediação do professor.

${ }^{3}$ Modelo interventivo que contempla um conjunto de princípios e estratégias, de base comportamental, que envolvem a estruturação do ambiente físico e uso de recursos visuais em ambientes de aprendizagem (MESIBOV, SHEA; SCHOPLER, 2006).

\section{Correspondência}

Maria da Guia Souza - Centro administrativo do estado, Av. Sen. Salgado Filho, s/n, Lagoa Nova, Natal, Rio Grande do Norte - Brasil

CEP: 59064-901

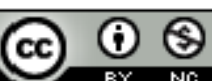

This work is licensed under a Creative Commons Attribution-NonCommercial 4.0 International (CC BY-NC 4.0) 